\title{
The Dialect and Cultural Implications of Jia Pingwa's Shaanxi Opera and the Ruined City
}

\author{
Tie Li
}

School of Foreign Studies, Xi'an University, 710065

Keywords: Jia Pingwa; Shaanxi Opera; Ruined City; Dialect; Cultural implications

\begin{abstract}
The value of literary works is largely related to the language of literature. Language is the foundation of literature. Jia Pingwa's Shaanxi Opera and Ruined City are excellent literary works where it is easy to find that a large number of Shaanxi dialect language is interspersed, which has an important significance in the embodiment of Shaanxi folk culture and the background of the central content.

The biggest feature of Shaanxi Opera and Ruined City is the usage of Shaanxi dialect, which is also a brilliant innovation in the two literary works. It is no doubt that Shaanxi Opera and Ruined City are excellent literary works with the value of appreciation and research. This paper makes an interpretation of the dialects used in the two works of Shaanxi Opera and Ruined City, and analyzes the literary and artistic value of dialect language in the two works.
\end{abstract}

\section{Introduction of the Author'S Life and Works}

Jia Pingwa is a famous contemporary provincial writer from Sanqin land. Most of his masterpieces are based on the rural life Sanqin land. This is related to his childhood experience with his parents living in rural Shaanxi. As Jia Pingwa's mother is Shangluo people, cultural influence since childhood leads to Jia Pingwa's works with a thick Shaanxi dialect, especially Shangluo dialect. Correspondingly, Sanqin local customs are commonly used as the background of Jia Pingwa's work. He truly recorded the stories occurring in Sanqin land with plain words, leisurely showing us the people's living conditions on the piece of the land. His works can be called as Shaanxi version of Riverside Scene at Qingming Festival.

The work of Shaanxi Opera was completed in 2005. Different from the previous novel, Shaanxi Opera does not have too many plots of ups and downs, but truthfully recorded three decades of change in the Qingfeng Street. Through recording the entanglement of Shaanxi Opera art between two big families Bai and Xia, the change of farmer's land, and the uncertainty of toiling masses, the work truthfully represents great change and strong impact of rural traditional life in social transformation. The article begins with the narrator Zhang Yinsheng to state his unrequited love with Bai Xue, thus leading to the various aspects of life of everybody in Qingfeng Street, and then transferring to the different experiences of Xia family members led by Xia Tianren. Shaanxi Opera, as the local opera of the inevitable decline, is brought out naturally by the experiences of Xia Tianzhi, Xia Feng, Bai Xue, and so on.

As a novel of early years, Ruined City is controversial from the beginning. The sick of behavior and mentality of the hero Butterfly is derived from the disillusionment and decadent of the inner world. When Jia Pingwa himself evaluats the creative motivation of Ruined City, he mentions that he wants to express the materialistic evil and human weakness. The article describes the life of the intellectuals in the cities of the northwest in the 1980s, thus reflecting the despair and greed of the expansion and loss of human hearts after the materialism prevailed. The work reflects from a unique perspective that in the economic and social transformation period, the weak foundations of the humanities leads to the change of mental behavior of part of the population. Through the vivid description of the morbid psychology of the hero Butterfly, the work profoundly depicts the dwarf and selfishness of the spiritual world of Butterfly, and at the same time, he glibly finds psychologically acceptable reasons and excuses for his own behavior. 


\section{An Interpretation of Dialect in Shaanxi Opera}

\section{The Dialect in the Folk Life}

Growing up in Shangluo area, Jia Pingwa has had the feeling of homesick mode on Sanqin land. In order to show the customs of the Sanqin land to the readers better, Jia Pingwa used a considerable number of dialects in his work. Language is a viable, and as the grass-roots organizational unit of a language, vocabulary undertakes the user's emotions in a broader sense.

The literary work, Shaanxi Opera, includes a number of dialects spoken in rural fields, so it represents readers a life picture scroll of rural area in Sanqin land which is vivid and substantial. One of the pieces of the work referred to the "wing". For those who are not familiar with the Shangluo area, the wing generally refers to the big house, just as $\mathrm{Du} F u$ said in his poem, "Where can I get a big broad shelter a thousand, ten thousand spans wide, huge roof that all the world's poor people can share with smiling faces?" And then for the Shangluo area, the wing has a different meaning. The wings in the Shangluo area is a distinctive geographical features of the house, often located in the courtyard of the side, back to the wall, after the house. Sanqin land locates in the Loess Plateau, so the walls are generally made by the repeated rammed loess. One side of the wing is connected with the wall, and other three sides are built by bricks, so it doesn't have a ridge. This kind of house is included in one of the Eight Fantasticalities in Shaanxi area. The wing is cool in summer and warm in winter, which is benefited from the sticky soil in Shangluo area with better wall supporting structures, thus to reduce the consumption of other building materials. In southern Shaanxi, the elderly usually live in the main house, and this wing is often used as storage room or bedroom of children and grandchildren.

\section{The Dialect in the Diet Culture}

There's an old adage that says, "Food the first necessity of man". Diet culture in China has a long history, so the cultural differences are often expressed as differences in the diet. The food commonly mentioned in Shaanxi Opera is including pancake and chili oil. The pancake is pasta in the Shaanxi area, which is baked to pot cover-shape. The pancake is easy to make and eat, and store. The raw material of chili oil is dried chili, and then the dried chili is pulverized and poured into boiling oil, and after stirring well, it can be served immediately. Chili oil is usually served with steamed bread or noodles, and can also serve alone as a dish. The common features of the pancake and chili oil are simple to produce, serve casually, easy to store, so they are often served together. The local people said that the people should wolf down the pancake with chili oil, which seems that the whole body has endless strength after eating, reflecting the local people's forthright character and the optimistic living attitude of fighting the nature, being fearless of danger and facing difficulty.

\section{The Re-Reading of Dialects in the Ruined City}

\section{The Arbitrariness of Language}

There were Zhao Shuli and Lao She who used dialect language in the novel early; and later it's not that rare. Jia Pingwa's language is rustic and natural. Jia Pingwa likes the ancient prose of fun, and he usually expresses the infinite meaning with clumsy language. He often infuses ancient languages and ancient prose style in the modem texts of the novels, which forms the style of writing between the ancient and modern. He portrays the characters while promoting the studies of Chinese ancient civilization, and foils and renders the environment and scenery, and simultaneously resumes the traditional culture. In view of this, the process of Jia Pingwa's novel creation is of exploring the practice of Chinese language. Jia Pingwa's language narrative way is between modern and classical Chinese. On one hand, it inherits the outstanding ideas of traditional literature of thousands of years; one the other hand, it is the absorption and reference of the outstanding achievements of the contemporary language. The choice of this approach between modern and classical Chinese is mainly due to the influence of the local dialects that the author has received during the growth 
process. It is precisely because Jia Pingwa properly uses the Sanqin and Shangluo dialects in the work of Ruined City, so as to make the characters of the novel profound. Jia Pingwa uses plain and funny language to describe the hero of the novel Butterfly to treat the materialistic society and the change of personality and the dwarfing of the inner world. This kind of unique language style makes it easier for the reader to understand and know the materialistic evil and human weakness of a considerable number of intellectuals represented by the hero in the socio-economic transition period. For writers, the innovation of language art usage ability largely depends on the ability of language proficiency, and multi-angle review ability makes the work language more vivid. The language of Ruined City is simple and humorous, and the smooth narration assists with dialects, of which the casual language contributes to the diversification of the language, bringing the readers' different reading experience and also achieving the work itself.

\section{Uniqueness of Language}

Common people evaluate that the personalization of literary language is a major achievement of the contribution of Jia Pingwa to the Chinese language and literature. He is not only good at using classical literature, but also can deftly handle modern literature. The deliberate performance of classical and modern literature has shown his language talent and also forms Jia Pingwa's unique language personality and style of writing. Jia Pingwa's own growth experience destined his diversified language style. He makes good use of language humor, which is not simply to make people laugh, but the emotional smile of the writer and readers. This thoughtful humor is not just the thought-provoking laughter, what more important, it enlightens readers to savor the philosophy of humor in laughter and rethink its meaning. Jia Pingwa always consciously pursues humor in the language of the novel, and inadvertently narrates the profound philosophy with humorous language against the preaching, which enlightens people in the ordinary. The artistic conception of the so-called rare voice of big sound, elephant invisible is more likely to be this way. Jia Pingwa forms a unique language feature with a non-standard language. As the language features in Ruined City, progressive language features are filled of historical concern. And the exact expression of environment and emotions in Ruined City is also benefited from the uniqueness of Jia Pingwa's language. The pristine Shangluo dialects in the birthplace of the Shangluo area and the vivid Xi'an dialects in the residence of Xi'an make Jia Pingwa's unique language both have massive real feelings and generate reader's humor inadvertently.

\section{Unique Cultural Implication in Shaanxi Opera}

\section{The Presentation of Strong and Noble Personality of Qin People}

Just like the old saying goes: Eight hundred li of Qinchuan has surrounding river and the mountains inside, three thousand li of Shaanxi Opera shakes heaven and earth. People often use this proverb to describe the resonant Shaanxi Opera around the mountains and rivers in Sanqin land. Infuriation and liberality are often used to describe Shaanxi Opera. Some people say that because of the vast eight hundred li of Qinchuan, Sanqin people are brought up with spirit to challenge nature and with happiness and can roar impassioned Shaanxi Opera to make the universe bear the weight of history. Born in a specific geographical background, Shaanxi Opera not only has the passionate and rough atmosphere, but also is one of the brightest colors in the history of Confucian culture. Therefore, people living here have both vividness in the South and boldness in the North, forming a unique considerate and gentle character. As advocated by Confucianism, both ends should be removed and the middle should be taken. It is the essence of Confucian doctrine of being dignified with vividness and astute without frivolity. As the capital of the twelve dynasties, Shaanxi went through ups and downs and dynasties change, and also developed its unique cultural connotation. Different from other ancient cities, Sanqin land contains the history and culture of the heavy atmosphere which is often deep in the streets, so that people inadvertently feel massiness and majesty. Therefore, in the context of this unique culture, Shaanxi's regional opera and dialect have a considerable degree of historical charm. Similar conclusion can also be obtained from the repertory of Shaanxi Opera. For 
example, the traditional repertory of the Shaanxi Opera "Execution at Outer Gate of Government Official ", is full of the hero Yang Yanjing's contradictions and complex inner scenes, of which the climax is to highlight Yang Yanjing in the treatment of loyalty and justice between the two conflicts, and the final outcome is also in line with the doctrine of the mean of Confucianism to make the two have organic integration. In fact, many of the traditional repertories of the Shaanxi Opera have a similar character that the hero of the play is often full of characters and vividness, and is very charismatic. Correspondingly, the lyrics and singing are also full of the doctrine of the mean which is bold and restrained organic combination.

\section{The Life Consciousness of Qin People under the Diverse Terrain}

The artistic traits of the Shaanxi Opera are originated from the diversification of the Sanqin land, especially the complex terrain of the area of Qin. The north of Sanqin land is endless loess plateau, which is a fragmented landform; the centre is Guanzhong plain, with abundant water and fertile land; the south is intermountain basin, circled with rivers. The diversity of complex terrain forms the unique artistic charm of the Shaanxi Opera. Only the Sanqin people in this piece of land will use a vehement way to roar out the earth-shaking Shaanxi Opera, so as to find the emotional resonance, vent their emotions, and inspire them. Sanqin people believe that they can eat without meat, but cannot give up roaring out Shaanxi Opera. The resonance in the Shaanxi Opera is bi-directional, and the emotion is not only the encouragement of the reader and the audience, but also the accumulation of the historical and cultural psychology of the Chinese nation. The roar of Shaanxi Opera is not only the praise, but also the indescribable emotion. As a local opera, Shaanxi Opera not only performs the local customs, but also shows the life consciousness of Sanqin people. Sanqin land is mainly divided into Guanzhong, northern Shaanxi and southern Shaanxi. Northern Shaanxi culture is the most attractive national culture of Sanqin land, such as enjoying singing and dancing on the Loess Plateau. Guanzhong region is flat. As the agricultural base is good, it is an area of great military importance. Eight hundred li of Qinchuan, as it is often claimed, mainly refers to the Guanzhong area. Southern Shaanxi is near to the Bashu. The climate is comfortable and humid. It is the important birthplace of Han culture in the history. In the era of changing circumstances, Liu Bang declared to be the emperor, and Liu Bei claim to be the king, which gave a legendary history to generations. The north and south of the culture is intersected at this place, making the Shaanxi Opera have both the rough atmosphere of the north and the vividness of the south. While combining the two masterly, it is the solemnity and vividness of the Sanqin land. Shaanxi Opera can be consistent in Shaanxi aesthetic, which is also because it combines the customs around Sanqin. Loud high pitch symbolizes the powerful northern Shaanxi; long-tone is like the honest of Guanzhong; and the brave of southern Shaanxi coincides with impassioned tone. The resonance of Sanqin people on Shaanxi Opera is also the inevitable result of a wide range of aesthetic of people in various regions.

\section{Conclusion}

As mentioned above, Jia Pingwa is a famous contemporary provincial writer from the Sanqin land, and his language features both have the characteristics of the southern agility and the northern boldness, forming a unique considerate and gentle character. As advocated by Confucianism, both ends should be removed and the middle should be taken. It is the essence of Confucian doctrine of being dignified with vividness and astute without frivolity. Correspondingly, Sanqin local customs are commonly used as the background of Jia Pingwa's work. He truly recorded the stories occurring in Sanqin land with plain words, leisurely showing us the people's living conditions on the piece of the land. Jia Pingwa has added a different landscape and color for Chinese contemporary literary world with simple and humorous words. 


\section{Acknowledgements}

This article is the positive result of the project of Xi'an Social Science Fund with the project name "Study on Cultural Soft Power in Translation of Shaanxi Regional Dialect under the background of 'One belt one road', project number 16WL17.

\section{Reference}

[1] L. Lu and M.X. Hao: A comparison of the narrative comparison between Jia Pingwa's Shaanxi Opera and Faulkner's The Sound and the Fury. Journal of Xi'an University of Architecture \& Technology (Social Science Edition), Vol. 01 (2014), p. 84. (In Chinese)

[2] W. Li: The family ethics in Jia Pingwa's local novels in recent years - Taking Shaanxi Opera, Gao Laozhuang and Tumen as examples. Literary and Artistic Contention, Vol. 03 (2014), p. 164. (In Chinese)

[3] Z.J. Huang and L. Shang: Contemporary writing of rural family culture - A case study of Jia Pingwa's Shaanxi Opera. Journal of Baoji University of Arts and Science (Social Science Edition), Vol. 03 (2009), p. 91. (In Chinese)

[4] H. Cheng and R.B. Li: The relationship between the Shaanxi Opera and the culture in Jia Pingwa's works. Journal of Weinan Teachers College, Vol. 11 (2012), p. 48. (In Chinese)

[5] S.S. Wu and P.X. Wu: The spiritual lack of local intellectuals in Jia Pingwa's novels - A case study of Turbulence, The Ruined City, Gao Laozhuang and Shaanxi Opera. Journal of Nanjing Xiaozhuang University, Vol. 03 (2015), p. 56. (In Chinese)

[6] J.J. Huang: Jia Pingwa's narrative pattern of madman, goddesses and city people - A case study of Shangzhou and Shaanxi Opera. Journal of North China Institute of Water Conservancy and Hydroelectric Power (Social Science Edition), Vol. 05 (2015), p. 125. (In Chinese)

[7] J.H. Zhang and S.C. Xue: Deep metaphors of farmers and land in the transitional period - A case study of Xia Tianyi in Jia Pingwa's novel Shaanxi Opera. Journal of Changjiang Normal University, Vol. 01 (2009), p. 97. (In Chinese)

[8] Y.N. Quan: From Ya Yan to Shaanxi Opera: Homeless return home - A new view on Jia Pingwa's novel Shaanxi Opera. Journal of Baoji University of Arts and Science (Social Science Edition), Vol. 04 (2006), p. 65. (In Chinese)

[9] L.L. Zhang: The elegy and distinctions of Chinese modern local life - Jia Pingwa's new works of Shaanxi Opera. Journal of Jining Teachers College, Vol. 05 (2006), p. 40. (In Chinese)

[10]C.L. Wang: The illumination of the countryside and the elegy of traditional culture - Jia Pingwa's novel Shaanxi Opera. Journal of Hainan Normal University (Social Science Edition), Vol. 05 (2005), p. 56. (In Chinese)

[11]X. Sun: Cultural anxiety and psychology: An existentialist interpretation of Shaanxi Opera The new changes of Jia Pingwa's local novels since the new century. Theory and Creation, Vol. 01 (2010), p. 69. (In Chinese)

[12] G. Cao: Jia Pingwa's local narrative and rhetoric aesthetics since the new century - Taking Shaanxi Opera, Ancient Furnace and Lao Sheng as the object of investigation. Novel Commentary, Vol. 03 (2016), p. 67. (In Chinese)

[13] H. Goldblatt: Ruined City (University of Oklahoma Press, USA 2016). 